\title{
Satellite Observed Aerosol Optical Thickness and Trend around Megacities in the Coastal Zone
}

\author{
Xuepeng Zhao \\ National Centers for Environmental Information (NCEI), NOAA/NESDIS, Asheville, NC 28801, USA \\ Correspondence should be addressed to Xuepeng Zhao; xuepeng.zhao@noaa.gov
}

Received 20 January 2015; Accepted 30 April 2015

Academic Editor: Liangfu Chen

Copyright ( 2015 Xuepeng Zhao. This is an open access article distributed under the Creative Commons Attribution License, which permits unrestricted use, distribution, and reproduction in any medium, provided the original work is properly cited.

\begin{abstract}
Nearly 30-year aerosol optical thickness (AOT) climate data record (CDR) derived from the operational satellite observations of National Ocean and Atmospheric Administration (NOAA) Advanced Very High Resolution Radiometer (AVHRR) is used to study the AOT trends over seventeen megacities in the coast zone (MCCZ). Linear trends are derived from monthly and seasonal mean AOT in the past three decades and used in the analysis. The results indicate the following: (1) AOT around a MCCZ in fast developing countries has relatively high value and a positive trend with a confidence level generally above 95\%; (2) AOT around a MCCZ in industrialized countries has relatively low value and a negative trend with a confidence level generally above 95\%; (3) AOT values and their trends show distinct seasonal variations in MCCZ, which can be explained somewhat by the seasonal variations of meteorological conditions. AOT trend is an effective index for examining the efficacy of air pollution control policies implemented for these megacities.
\end{abstract}

\section{Introduction}

About half of the world's population lives in urban areas today due to convenient living facilities and the opportunity of a better quality of life, driving the formation of many rapidly growing urban centers or agglomerations, called megacities. Here, a megacity is defined as a large urban agglomeration with populations exceeding 10 million inhabitants. The majority of these urban megacities are located in a coastal zone or a zone with distinct coastal influence [1], which are called megacities in the coastal zone (MCCZ) hereafter. The concentrations of people in MCCZ and the related human activities (e.g., construction, transportation, energy generation, industrial production, etc.) pose serious challenge to the ecological environment of MCCZ $[1,2]$. For example, air and water pollutions associated with human activities have become one of the most imminent environmental issues of MCCZ in recent decades [3-6], especially in the developing countries where limited resources are available for addressing the pollution issues.

The scale of air and water pollutions in MCCZ can be hundreds to thousands of kilometers in the atmosphere and tens to hundreds of kilometers in the ocean and has the potential to contribute significantly to climate change $[1,7-$ 10]. Long-term continuous monitoring and analysis on the distribution and evolution of air pollutants are the necessary effort to better manage, control, and mitigate the air pollution in MCCZ $[7,11]$. One primary reason for monitoring ambient air pollutants is to provide information for estimating their potential effects, particularly on environmental and human health. Considering that satellite remote sensing can detect air pollutants and track their transport from local and regional scales to the globe, long-term satellite observations of air pollution have been identified as an effective measurement to characterize air pollution in MCCZ $[6,7]$.

One of the most important ambient air pollutants is particulate matter (PM), which refers to tiny pieces of solid or liquid particles suspended in the air and is also called atmospheric aerosols. Aerosols in urban environment not only cause serious air quality and health issues but also serve as important cooling and warming agent for climate change due to its scattering and absorbing of solar and earth radiations [9] and serving as cloud condensation nuclei (CCN) [12]. Aerosol optical thickness (AOT) can be used 


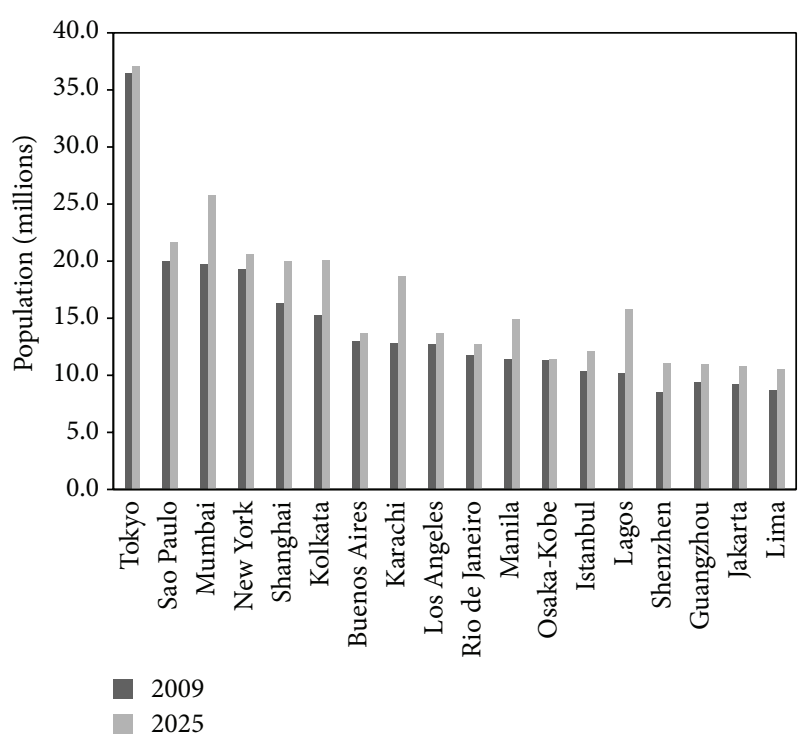

FIGURE 1: Identified seventeen megacities in the coastal zone (MCCZ) in the study and their population in 2009 and 2025, respectively.

as an effective optical measure of PM amount for urban air pollution. In general, a high or low AOT value corresponds to a high or low PM amount assuming most of the aerosols are near ground or in planetary boundary layer $(\mathrm{PBL})$ in an urban environment. Thus, long-term observation of AOT over MCCZ from satellite can provide information on the changes and trends of air pollution, which can be used to evaluate the efficiency of the measures and polices implemented for air pollution control and air quality improvement in MCCZ.

In this paper, we will analyze AOT and its trend around MCCZ observed in the past three decades from the Advanced Very High Resolution Radiometer (AVHRR) onboard polar operational satellites of National Ocean and Atmospheric Administration (NOAA). The paper is arranged as follows: Section 2 introduces selected MCCZ and the AVHRR satellite AOT data; trend analysis approach is briefly described in Section 3; variation of monthly mean AOT and its trend for the selected MCCZ are studied in Section 4; seasonal features of AOT and its trend are examined in Section 5; summary and conclusions are given in the close section.

\section{Selected MCCZ and Satellite Data}

Seventeen urban centers in the coastal zone with inhabitants going to exceed 10 million in 2025 are selected as MCCZ in our current study. Figure 1 shows the population of these 17 MCCZ in 2009 and 2025, respectively, based on the data of United Nations $[1,13]$. Among these megacities, there are five (Tokyo, Osaka-Kobe, New York, Los Angeles, and Istanbul) in developed countries and the rest are in developing countries. There are five megacities (Sao Paulo, Rio de Janeiro, Buenos Aires, Lima, and Jakarta) in the south hemisphere ( $\mathrm{SH}$ ) and the others are in the north hemisphere $(\mathrm{NH})$. Fifteen out of the seventeen megacities are in the coastal zone of tropical or subtropical regions and the other two (New York and Istanbul) are in the coasts of $\mathrm{NH}$ temperate zone.

Version 2 of NOAA operational AVHRR satellite AOT climate data record (CDR) $[14,15]$ is used in this study. AVHRR AOT CDR is derived over global water (or ocean) surface at $0.63 \mu \mathrm{m}$ channel using a two-channel AVHRR aerosol retrieval algorithm [16] from the AVHRR clear-sky reflectance, which is determined from the NOAA Pathfinder Atmospheres-Extended (PATMOS-x) AVHRR all-sky reflectance and cloud probability CDR products [17]. The PATMOS-x AVHRR reflectance has been intercalibrated with MODIS reflectance and retrospectively calibrated among all the AVHRR sensors used in the AOT CDR production so that the calibration accuracy is improved to $\sim 3 \%$, which is close to MODIS accuracy of 2\% [17].

Due to limited channels of AVHRR instrument, only aerosol retrieval over waters can be obtained and only AOT retrieved from $0.63 \mu \mathrm{m}$ channel achieves a climate quality since the retrieval from wider $0.86 \mu \mathrm{m}$ channel is contaminated by water vapor absorption, which is difficult to be accurately quantified, especially in the case of AOT trend detection. The retrieval algorithm has been validated by comparing with the AERONET ground AOT measurement [16, 18]; specifically, surface AOT observations from AERONET coastal stations had been used to validate our AOT retrieval algorithm and the aerosol model and surface reflectance were adjusted to achieve best validation results as demonstrated in our validation works $[16,18]$. In our validation, satellite (ST) aerosol optical thickness values $\left(\tau_{\text {st }}\right)$ are matched up with the corresponding "truth" values derived from the same day surface AERONET sun-photometer (SP) observations $\left(\tau_{\mathrm{sp}}\right)$ at coastal stations. They are statistically processed within an optimum space-time window from which scatter diagram of $\tau_{\mathrm{st}}$ versus $\tau_{\mathrm{sp}}$ is produced. Linear regression analyses are performed, predicting the satellite retrieved values of $\tau_{\text {st }}$ as a function of the SP values of $\tau_{\text {sp }}$ in the form of $\tau_{\text {st }}=A+$ $B \tau_{\mathrm{sp}}$. Retrieval algorithm performance can be evaluated from resulting statistical parameters of the linear regression: $A$ (intercept), $B$ (slope), $\delta$ (standard error), and $R^{2}$ (square of correlation coefficient). For example, a nonzero intercept tells us the retrieval algorithm is biased at low AOT values, which is mainly associated with improper assumptions about ocean surface reflection (including the contamination associated with sediment in Case II water in coastal regions) after sensor calibration error has been minimized through intercalibration. A slope that is different from unity (proportional error) indicates that there is some inconsistency between the aerosol microphysical model (mainly refractive index) used in the retrieval algorithm and that in the real world.

Corresponding input satellite reflectances and retrieval geometrical conditions are also collected in the match-up validation data set; thus, we were able to adjust the ocean surface reflectance and aerosol model and redo the AOT retrieval for the collected match-up data to obtain updated match-up $\tau_{\text {st }}$ data. Then we perform linear regression analyses again and obtain new statistical parameters of the linear regression: $A, B, \delta$, and $R^{2}$. This adjustment and linear regression are repeated until obtained $A$ is nearly zero and $B$ is close to unity. 


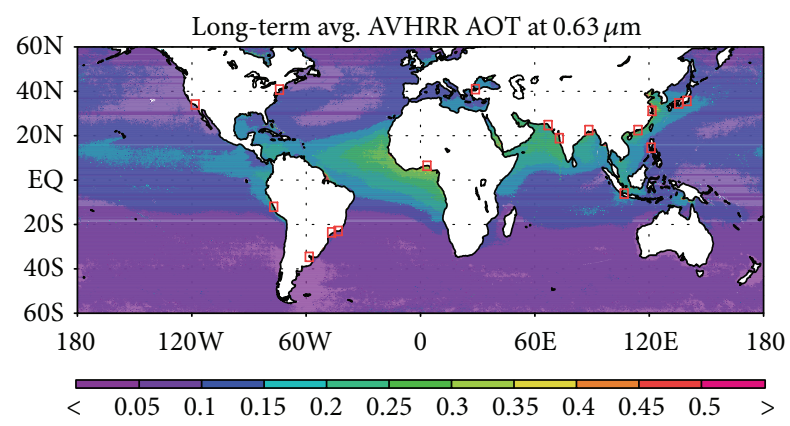

FIGURE 2: Global map of temporal averaged (1981-2009) monthly mean AOT along with the locations of seventeen MCCZ marked by red square boxes.

The corresponding surface reflectance and aerosol model are optimized and used in the retrieval algorithm. As a result, the surface contamination from various sources (including the contamination associated with sediment in Case II water in coastal regions) on the AOT retrieval is corrected and minimized in a collective way rather than individually. Please refer to $[16,18]$ for more detailed explanation.

The AOT values in the coastal regions shown in Figure 2 clearly demonstrate the effectiveness of removing the surface reflectance contamination; otherwise high AOT values will be over all the coast regions. The comparison with the MODIS satellite AOT observation [19] also indicated that our AOT retrieval over ocean has similar performance as the standard MODIS AOT retrieval if the same MODIS observed radiances are used as the input radiances. The algorithm had been applied to both previous and current versions of the PATMOS-x reflectance to generate long-term AOT data for the study of AOT long-term trend over global and regional scales $[20,21]$. We will extend the study to local scale in this work.

Residual cloud contamination on AOT has been greatly reduced in version 2 AVHRR AOT CDR product compared to previous version and is more reliable for AOT trend study [15]. Global AVHRR AOT $(0.63 \mu \mathrm{m})$ CDR product from 1981 to 2009 in $0.1 \times 0.1$ degree equal angle grid is used in this study. Two and a half years of data after the major volcano eruptions of El Chichón in March 1982 and Mt. Pinatubo in June 1991 are discarded in the trend analysis to remove the abrupt AOT perturbations [20].

Figure 2 shows the global map of temporal (1981-2009) averaged AOT along with the locations of seventeen MCCZ marked by red square boxes. It is seen that AOT values over the coastal oceanic surface around these MCCZ are generally higher than over the remote open ocean due to the downwind transport of aerosols originated from urban pollution. Thus, the changes and trends of AOT over the coastal ocean surface around these MCCZ can be used effectively to track the changes and trends of PM over these MCCZ.

\section{AOT Linear Trend Analysis}

In this paper, we only study the statistical linear tendency of AOT for selected MCCZ. The real tendencies of AOT may be much more complex than the statistical linear model. However, the linear trend allows a simple approximation of the direction and magnitude of the changes in the data and may be adequate for many practical purposes. Results from the linear trend studies are not only commonly used by scientists but also familiar to policy makers and the public. Thus, it is important to examine the climate change issues under such a linear model. Actually, we have successfully applied this linear trend analysis on the investigation of global and regional AOT changes and trends in some previous studies $[15,20,21]$.

Here, we only give a brief description on the linear trend analysis used in this study and detailed description of linear trend analysis can be found in the literature [2224]. The linear change of a variable, such as AOT, is often measured with the linear trend (LT) in the unit of absolute (or percentage) changes per decade. AOT LT is the slope of the linear regression line for the time series of monthly averaged AOT. We adopt the commonly used decision rule that a detectable trend is indicated, at the $5 \%$ significance level or $95 \%$ confidence level, when $|\mathrm{LT} / \sigma|>2$ [23]. Here $\sigma$ is the standard deviation of AOT LT. It is difficult to determine $\sigma$ from the observational data directly so that, as a firstorder approximation, we will use the standard deviation $(\varepsilon)$ of monthly averaged AOT as $\sigma$ after adjusting the unit of $\varepsilon$ to match the unit of LT. We further name LT/ $\sigma$ ratio as the "significance" of AOT LT in this paper. A significance $>+2$ (or $<-2$ ) indicates the increasing (or decreasing) tendency detected is above $95 \%$ confidence level. For each MCCZ, AOT observation within $\pm 1^{\circ}$ latitude/longitude spatial window around the megacity is used for the analysis of AOT variation and trend. The spatial window is in square shape with the center located at MCCZ latitude/longitude listed in Table 1 and the four sides are $2^{\circ}$ wide in both latitudinal and longitudinal directions. This optimal window size is determined from sensitive tests for both retaining the signal of city influence in AOT and providing sufficient observation sampling numbers for statistical analysis.

\section{Monthly Mean AOT and Trend}

As an example, the AOT time series of the two cities with the most distinct negative trend and positive trend, respectively, are shown in Figure 3. Table 1 summarizes the linear trend and its significance along with temporal averaged (19812009) AOT values for the seventeen MCCZ. It is seen that AOT in Jakarta, Mumbai, Karachi, Lagos, Buenos Aires, Shanghai, Kolkata, and Shenzhen have positive trends either above or close to $95 \%$ confidence level for the past three decades. These MCCZ are in the developing countries, where limited pollution control is performed due to lack of strategic planning and resources as well as relatively low public concern on the pollution issues compared to the concern on the improvement of living condition and convenience, such as job, housing, and transportation $[3,4,7,25]$.

Shanghai and Buenos Aires are the two cities with the highest temporal averaged AOT value (or climatology value) while Jakarta and Mumbai are the two cities with the most 
TABLE 1: AOT linear trend (LT) and its significance (LT/ $\sigma$ ) and temporal averaged (1981-2009) monthly mean AOT values for the seventeen MCCZ along with their geolocation and projected population in 2025.

\begin{tabular}{|c|c|c|c|c|c|c|}
\hline Number & Megacity & $\begin{array}{c}\text { AOT LT } \\
\text { (1/decade) }\end{array}$ & $\begin{array}{c}\text { Significance } \\
\text { of LT }\end{array}$ & Averaged AOT & $\begin{array}{c}\text { Geolocation } \\
\text { (longitude, latitude) }\end{array}$ & $\begin{array}{l}\text { Population in } \\
2025 \text { (million) }\end{array}$ \\
\hline 1 & Tokyo & -0.092 & -1.78 & 0.21 & $139.77^{\circ}, 35.68^{\circ}$ & 37 \\
\hline 2 & Mumbai & 0.489 & 4.85 & 0.44 & $72.82^{\circ}, 18.90^{\circ}$ & 26 \\
\hline 3 & Sao Paulo & -0.231 & -3.14 & 0.20 & $-46.63^{\circ},-23.55^{\circ}$ & 22 \\
\hline 4 & New York & -0.439 & -7.66 & 0.17 & $-73.94^{\circ}, 40.78^{\circ}$ & 21 \\
\hline 5 & Shanghai & 0.333 & 1.98 & 0.78 & $121.43^{\circ}, 31.20^{\circ}$ & 20 \\
\hline 6 & Kolkata & 0.595 & 1.80 & 0.58 & $88.33^{\circ}, 22.53^{\circ}$ & 20 \\
\hline 7 & Karachi & 0.258 & 3.42 & 0.31 & $66.98^{\circ}, 24.80^{\circ}$ & 19 \\
\hline 8 & Lagos & 0.258 & 2.26 & 0.40 & $3.40^{\circ}, 6.45^{\circ}$ & 16 \\
\hline 9 & Manila & -0.084 & -1.61 & 0.13 & $120.98^{\circ}, 14.58^{\circ}$ & 15 \\
\hline 10 & Buenos Aires & 0.436 & 2.01 & 0.77 & $-58.37^{\circ},-34.58^{\circ}$ & 14 \\
\hline 11 & Los Angeles & -0.229 & -5.99 & 0.12 & $-118.25^{\circ}, 34.05^{\circ}$ & 14 \\
\hline 12 & Rio de Janeiro & -0.302 & -4.92 & 0.18 & $-43.23^{\circ},-22.90^{\circ}$ & 13 \\
\hline 13 & Istanbul & -0.761 & -12.85 & 0.20 & $28.83^{\circ}, 40.97^{\circ}$ & 12 \\
\hline 14 & Osaka Kobe & 0.005 & 0.10 & 0.21 & $135.50^{\circ}, 34.53^{\circ}$ & 11 \\
\hline 15 & Shenzhen & 0.173 & 1.45 & 0.42 & $114.13^{\circ}, 22.53^{\circ}$ & 11 \\
\hline 16 & Jakarta & 0.450 & 6.21 & 0.26 & $106.83^{\circ},-6.10^{\circ}$ & 11 \\
\hline 17 & Lima & 0.059 & 1.08 & 0.25 & $-77.03^{\circ},-12.05^{\circ}$ & 11 \\
\hline
\end{tabular}

distinct positive trend in AOT. This suggests that current air quality in Shanghai and Buenos Aires is much easier to reach the unhealthy level defined by World Health Organization (WHO) than in Jakarta and Mumbai but air quality degrades much faster with time in Jakarta and Mumbai than in Shanghai and Buenos Aires. There is a high potential that air quality will become worse in Jakarta and Mumbai than in Shanghai and Buenos Aires in the future if the trends stay the same.

AOT climatology value of Mumbai (0.44) is almost two times larger than that of Jakarta (0.26) and the magnitude of seasonal extremes observed in Figure 3(d) (Mumbai) is also larger than that in Figure 3(c) (Jakarta). This suggests that there is more chance that air quality may reach to WHO unhealthy level in Mumbai than in Jakarta even though the positive trend of AOT in Jakarta is more evident than in Mumbai. Thus, both AOT climatology value and AOT trend are information needed to better assess the air quality issue of a MCCZ.

AOT in Istanbul, New York, Los Angeles, Rio de Janeiro, and Sao Paulo have negative trend with a confidence level above $95 \%$ for the past three decades and their AOT climatology values are also at the low end of seventeen MCCZ AOT climatology values. These megacities are either in the developed countries (Istanbul, New York, and Los Angeles) with more stringent policies implemented for pollution emissions or in popular coastal tourism cities (Rio de Janeiro and Sao Paulo) where more stringent air pollution measures are implemented by the city government due to the concerns of tourism business and general public [2, 7, 25]. For the other cities, even though the monthly AOT show some trends (either positive or negative), their significance is generally below 95\% confidence level.

\section{Seasonal Variation of AOT and Trend}

Due to the seasonal changes of pollution emissions and meteorological conditions in a MCCZ, AOT and its trend may also display seasonal variations accordingly. Thus, examining the seasonal variations of AOT and its trend for a MCCZ should provide more insightful information on the pollution conditions and scenarios. The following seasonal analysis focuses on the eleven MCCZ where the positive or negative trend of monthly mean AOT discussed in the above section is at a confidence level close to or above 95\%. The eleven megacities are Jakarta, Shanghai, Karachi, Mumbai, Lagos, Istanbul, New York, Los Angeles, Buenos Aires, Sao Paulo, and Rio de Janeiro.

Figure 4 shows the significance (LT/ $\sigma$ ) of monthly and seasonal AOT linear trends and temporal averaged seasonal mean AOT values for the identified eleven megacities in a bar plot. Relatively high seasonal mean AOT values along with evident seasonal variations are observed in Shanghai, Karachi, Mumbai, Lagos, and Buenos Aires, especially in Shanghai and Buenos Aires. Air quality in Shanghai is strongly influenced by on-shore wind condition in later summer and earlier fall and off-shore wind condition in later winter and earlier spring, which produces low AOT in summer and fall relative to high AOT in winter and spring along with a positive trend above 95\% confidence level in winter. For Buenos Aires, air quality is the worst in cold season due to stagnant wind and strong shallow 


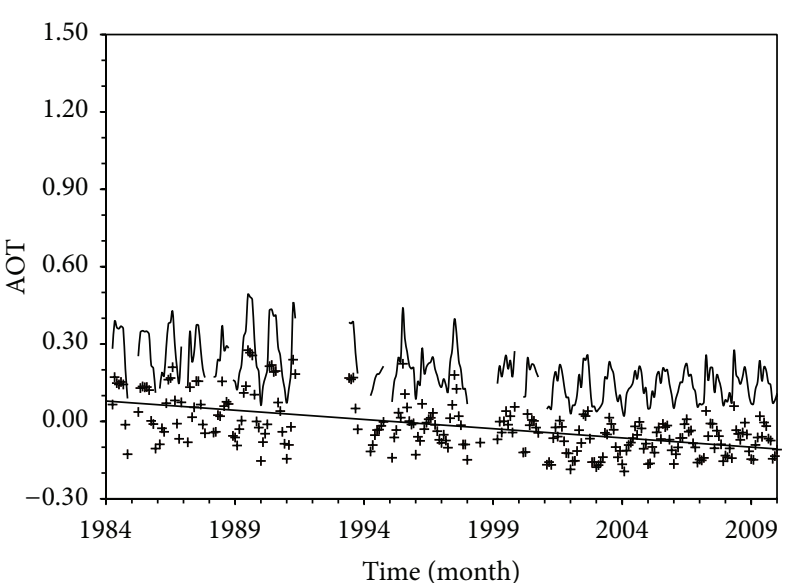

(a)

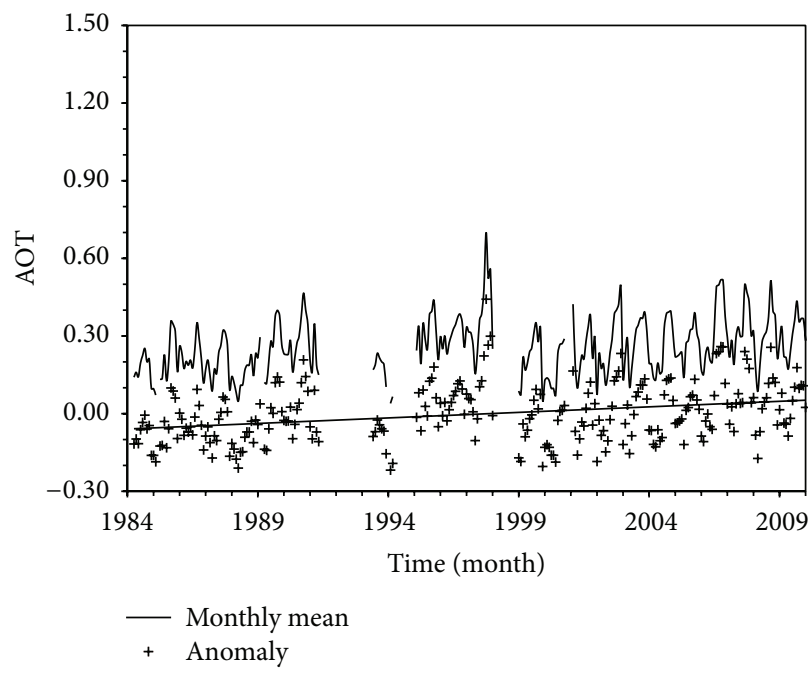

(c)

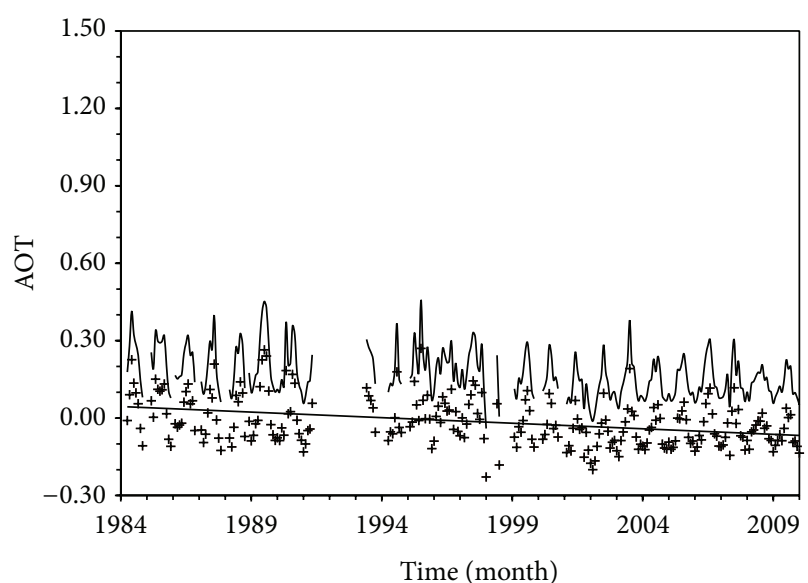

(b)

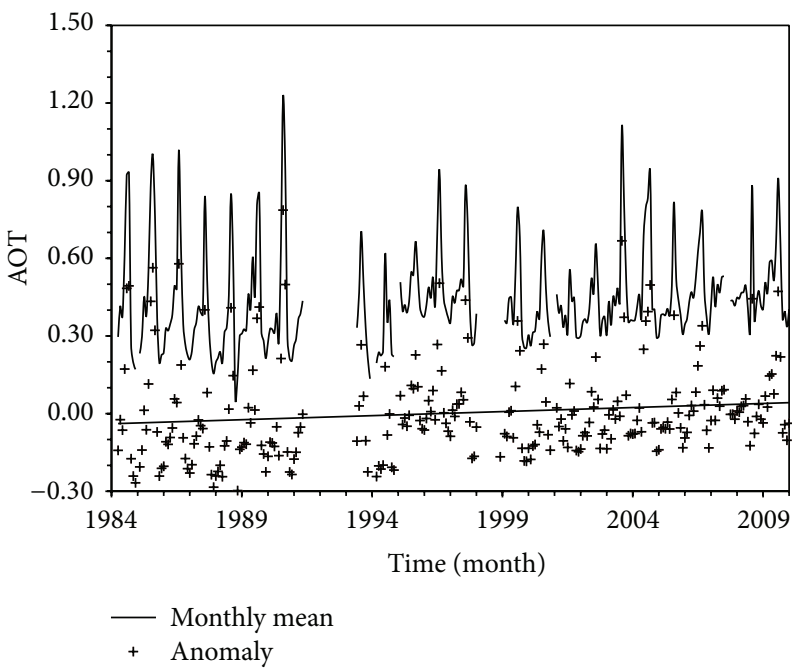

(d)

Figure 3: Examples of time series (dark curve) of monthly mean AOT for (a) Istanbul, (b) New York, (c) Jakarta, and (d) Mumbai. Plus symbols are the departure (or anomaly) from the climatology and the linear trend is shown as the dark straight line.

temperature inversion conditions but greatly improved in warm season due to moderate and strong winds buffeting the city throughout most of the summer, which explains the highest AOT in winter season. However, the seasonal trend is negative in winter and positive in summer but both are somewhat below $95 \%$ confidence level.

Air quality in Indian Peninsula is heavily influenced by Indian monsoon circulation and precipitation. As a result, local urban pollution in Mumbai and Karachi is much worse in winter than in summer due to the washout of pollutants by the strong precipitation associated with Indian summer monsoon, which results in distinct positive trends (above 95\% confidence level) of seasonal mean AOT in nonmonsoon seasons for the two cities. However, due to the intrusion of dusty air in later spring and summer, which is transported from Arabian Peninsula and East Africa by monsoon circulation, seasonal mean AOT value is actually higher in summer and spring than in the other two seasons. Seasonal mean AOT in Lagos is higher in winter and spring than in summer and fall, which is consistent with the distinct dry (November to
April) and rainy (May to October) seasons in Lagos. However, the trends of season mean AOT are positive in all seasons but below 95\% confidence level. In Jakarta, AOT is higher in summer and fall than in winter and spring. AOT trends are positive in all seasons and the confidence level in summer and fall is well above $95 \%$.

For Istanbul, New York, and Los Angeles, AOT negative trends are above $95 \%$ confidence level for all four seasons and temporal averaged seasonal mean AOT values are at the low end of eleven MCCZ. This suggests that stringent pollution control and emission criteria implemented during the past three decades for these MCCZ in developed countries are highly effective for improving air quality for all seasons. The seasonal variations of AOT in Sao Paulo and Rio de Janeiro are very similar with high AOT in cold seasons (fall and winter) and low AOT in warm seasons (spring and summer). However, the variations of their seasonal AOT trend are different. For example, the highest (above 95\% confidence level) and lowest (below 95\% confidence level) negative seasonal trends are observed in summer and fall, respectively, 


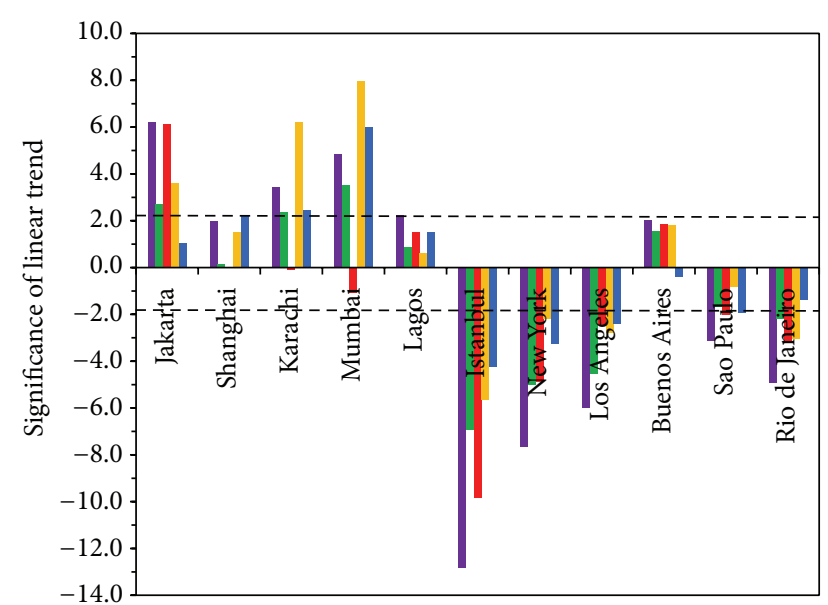

(a)

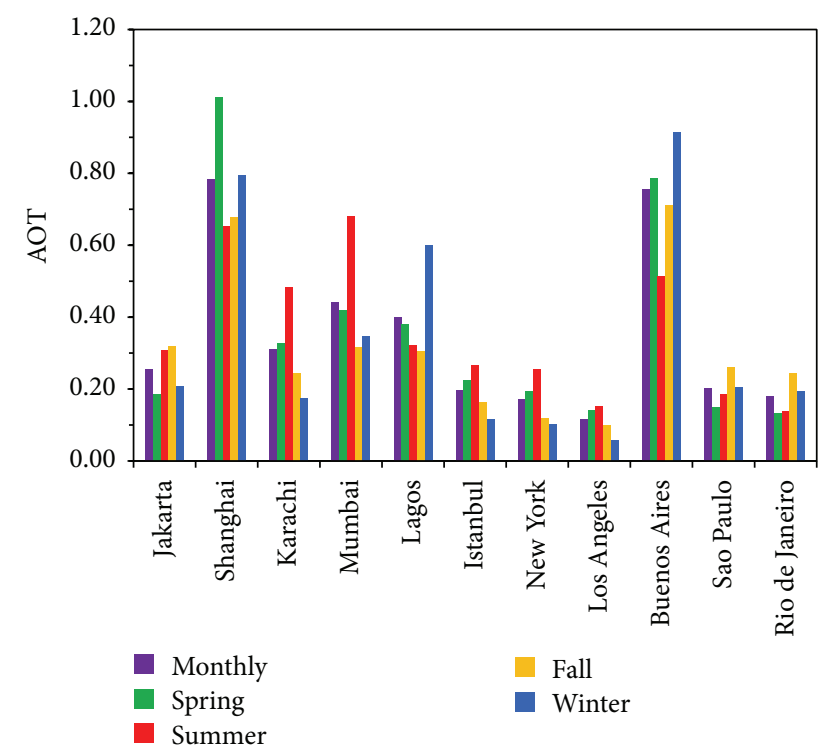

(b)

FIgURE 4: (a) The significance of linear trends of monthly and seasonal mean AOT and (b) temporal averaged seasonal mean AOT values for the eleven megacities where the positive or negative trend of monthly mean AOT is at a confidence level close to or above $95 \%$.

in Sao Paulo, while the corresponding seasons are summer and winter, respectively, in Rio de Janeiro. Negative AOT trends in all four seasons (even though not all above 95\% confidence level) for these two coastal tourism cities also suggest that the policy of air pollution control carried out by the two city governments during the past three decades is generally effective for improving air quality.

The above seasonal analyses of AOT variations and trends in the MCCZ suggest that seasonal variations of meteorological condition have a more direct effect on the AOT variations than on its trends.

\section{Summary and Conclusion}

Nearly 30-year AOT climate data record derived from NOAA AVHRR operational satellites observations is used to study the AOT trends over seventeen megacities in the coast zone. Linear trend is derived from monthly and seasonal mean AOT in the past three decades and used in our analysis. AOT around the MCCZ in fast developing countries generally has positive trend with a confidence level above $95 \%$ and relatively high AOT value while AOT around the MCCZ in industrialized countries generally has negative trend with a confidence level above 95\% and relatively low AOT value. AOT values and their trends show distinct seasonal variation, which can be explained somewhat by the seasonal variation of meteorological condition, especially for the variation of AOT values.

Combined analysis of AOT variations and trends is useful to reveal the air quality condition in a MCCZ and is effective for assessing the efficiency of the air pollution control policies and measures implemented. For a megacity with a higher AOT and distinct positive trend (e.g., Shanghai), it is relatively easy for air quality to reach and degrade to WHO unhealthy level, while for a megacity with a lower AOT and distinct negative trend (e.g., New York), it is relatively rare for air quality to reach and degrade to WHO unhealthy level. This study demonstrates that, similar to global and regional air pollution applications, continuous global long-term satellite observation of AOT is also useful for local urban air quality applications.

\section{Conflict of Interests}

The author declares that there is no conflict of interests regarding the publication of this paper.

\section{Acknowledgments}

This work is supported by the NOAA Climate Data Record (CDR) Program at National Centers for Environmental Information (NCEI). Constructive comments and suggestions from four anonymous reviewers are greatly appreciated.

\section{References}

[1] R. von Glasow, T. D. Jickells, A. Baklanov et al., "Megacities and large urban agglomerations in the coastal zone: interactions between atmosphere, land, and marine ecosystems," Ambio, vol. 42, no. 1, pp. 13-28, 2013.

[2] I. Sekovski, A. Newton, and W. C. Dennison, "Megacities in the coastal zone: using a driver-pressure-state-impact-response framework to address complex environmental problems," Estuarine, Coastal and Shelf Science, vol. 96, no. 1, pp. 48-59, 2012.

[3] D. Mage, G. Ozolins, P. Peterson et al., "Urban air pollution in megacities of the world," Atmospheric Environment, vol. 30, no. 5, pp. 681-686, 1996.

[4] S. K. Guttikunda, G. R. Carmichael, G. Calori, C. Eck, and J.-H. Woo, "The contribution of megacities to regional sulfur pollution in Asia," Atmospheric Environment, vol. 37, no. 1, pp. 11-22, 2003.

[5] D. D. Parrish and T. Zhu, "Clean air for megacities," Science, vol. 326, no. 5953, pp. 674-675, 2009. 
[6] M. Kanakidou, N. Mihalopoulos, T. Kindap et al., "Megacities as hot spots of air pollution in the east mediterranean," Atmospheric Environment, vol. 45, no. 6, pp. 1223-1235, 2011.

[7] M. J. Molina and L. T. Molina, "Megacities and atmospheric pollution," Journal of the Air \& Waste Management Association, vol. 54, no. 6, pp. 644-680, 2004.

[8] B. R. Gurjar and J. Lelieveld, "New directions: megacities and global change," Atmospheric Environment, vol. 39, no. 2, pp. 391393, 2005.

[9] V. Ramanathan, P. J. Crutzen, J. T. Kiehl, and D. Rosenfeld, "Atmosphere: aerosols, climate, and the hydrological cycle," Science, vol. 294, no. 5549, pp. 2119-2124, 2001.

[10] M. G. Lawrence and J. Lelieveld, "Atmospheric pollutant outflow from southern Asia: a review," Atmospheric Chemistry and Physics, vol. 10, no. 22, pp. 11017-11096, 2010.

[11] J. C. Chow, J. G. Watson, J. J. Shah et al., "Megacities and atmospheric pollution," Journal of the Air \& Waste Management Association, vol. 54, no. 10, pp. 1226-1235, 2004.

[12] J. D. Whitehead, G. McFiggans, M. W. Gallagher, and M. J. Flynn, "Simultaneous coastal measurements of ozone deposition fluxes and iodine-mediated particle emission fluxes with subsequent CCN formation," Atmospheric Chemistry and Physics, vol. 10, no. 1, pp. 255-266, 2010.

[13] UN DESA, "World urbanization prospects: the 2009 revision," Tech. Rep., United Nations Department of Economic and Social Affairs and Population Division, 2010.

[14] P. K. Chan, X.-P. Zhao, and A. K. Heidinger, "Long-term aerosol climate data record derived from operational AVHRR satellite observations," Dataset Papers in Geosciences, vol. 2013, Article ID 140791, 5 pages, 2013.

[15] T. X. P. Zhao, P. K. Chan, and A. K. Heidinger, "A global survey of the effect of cloud contamination on the aerosol optical thickness and its long-term trend derived from operational AVHRR satellite observations," Journal of Geophysical Research D: Atmospheres, vol. 118, no. 7, pp. 2849-2857, 2013.

[16] T. X.-P. Zhao, O. Dubovik, A. Smirnov et al., "Regional evaluation of an advanced very high resolution radiometer (AVHRR) two-channel aerosol retrieval algorithm," Journal of Geophysical Research D: Atmospheres, vol. 109, no. 2, Article ID D02204, 2004.

[17] A. K. Heidinger, M. J. Foster, A. Walther, and X.-P. Zhao, "The pathfinder atmospheres-extended avhrr climate dataset," Bulletin of the American Meteorological Society, vol. 95, no. 6, pp. 909-922, 2014.

[18] T. X.-P. Zhao, I. Laszlo, B. N. Holben, C. Pietras, and K. J. Voss, "Validation of two-channel VIRS retrievals of aerosol optical thickness over ocean and quantitative evaluation of the impact from potential subpixel cloud contamination and surface wind effect," Journal of Geophysical Research D: Atmospheres, vol. 108, no. 3, pp. 4106-4117, 2003.

[19] T. X.-P. Zhao, I. Laszlo, P. Minnis, and L. Remer, "Comparison and analysis of two aerosol retrievals over the ocean in the Terra/Clouds and the Earth's Radiant Energy SystemModerate Resolution Imaging Spectroradiometer single scanner footprint data: 1. Global evaluation," Journal of Geophysical Research D: Atmospheres, vol. 110, no. 21, Article ID D21208, 15 pages, 2005.

[20] T. X.-P. Zhao, I. Laszlo, W. Guo et al., "Study of long-term trend in aerosol optical thickness observed from operational AVHRR satellite instrument," Journal of Geophysical Research D: Atmospheres, vol. 113, no. 7, Article ID D07201, 2008.
[21] X.-P. Tom Zhao, A. K. Heidinger, and K. R. Knapp, "Long-term trends of zonally averaged aerosol optical thickness observed from operational satellite AVHRR instrument," Meteorological Applications, vol. 18, no. 4, pp. 440-445, 2011.

[22] G. C. Tiao, G. C. Reinsel, D. M. Xu et al., "Effects of autocorrelation and temporal sampling schemes on estimates of trend and spatial correlation," Journal of Geophysical ResearchAtmospheres, vol. 95, no. D12, pp. 20507-20517, 1990.

[23] E. C. Weatherhead, G. C. Reinsel, G. C. Tiao et al., "Factors affecting the detection of trends: statistical considerations and applications to environmental data," Journal of Geophysical Research D: Atmospheres, vol. 103, no. 14, pp. 17149-17161, 1998.

[24] D. S. Wilks, Statistical Methods in the Atmosphere Sciences, Academic Press, San Diego, Calif, USA, 1995.

[25] B. R. Gurjar, T. M. Butler, M. G. Lawrence, and J. Lelieveld, "Evaluation of emissions and air quality in megacities," Atmospheric Environment, vol. 42, no. 7, pp. 1593-1606, 2008. 

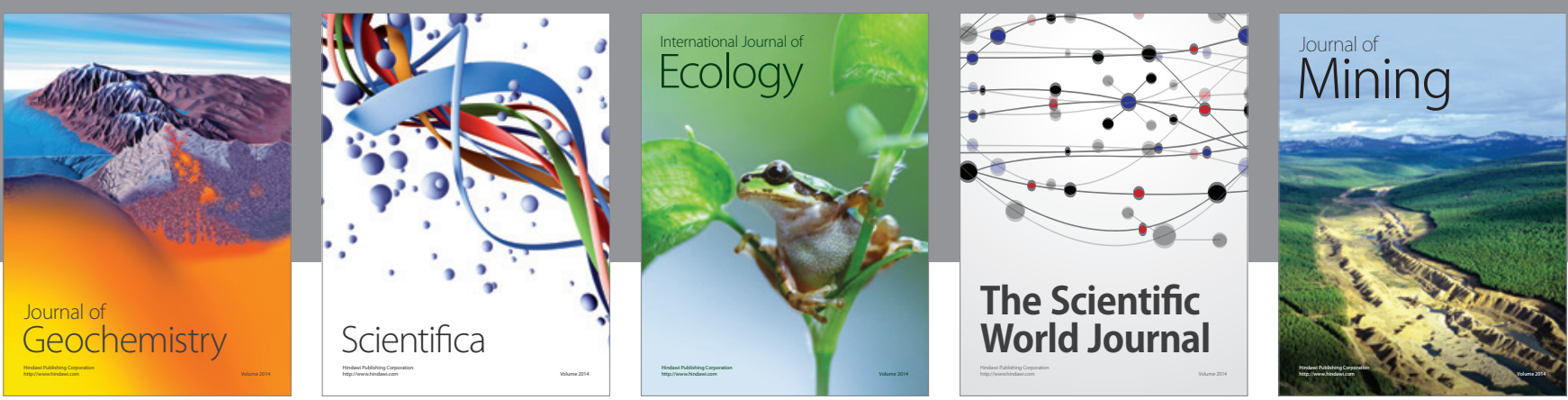

The Scientific World Journal
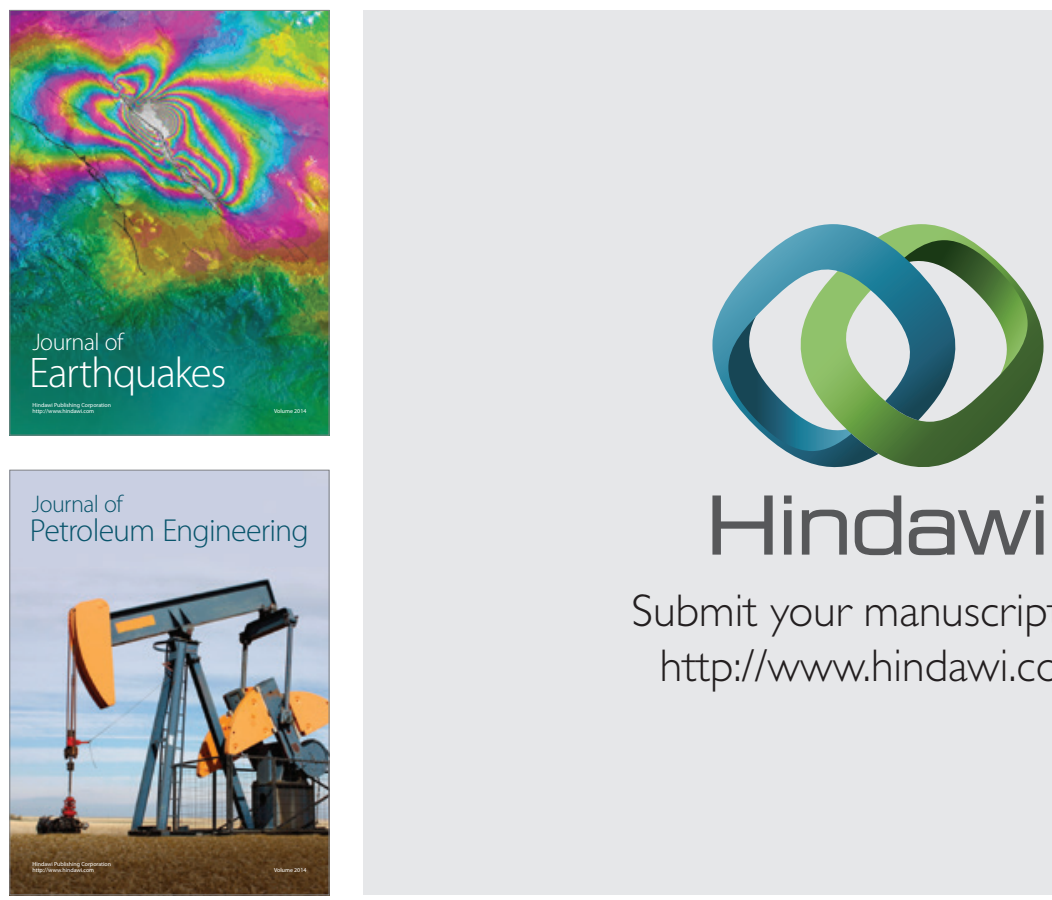

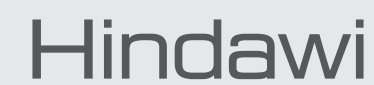

Submit your manuscripts at

http://www.hindawi.com
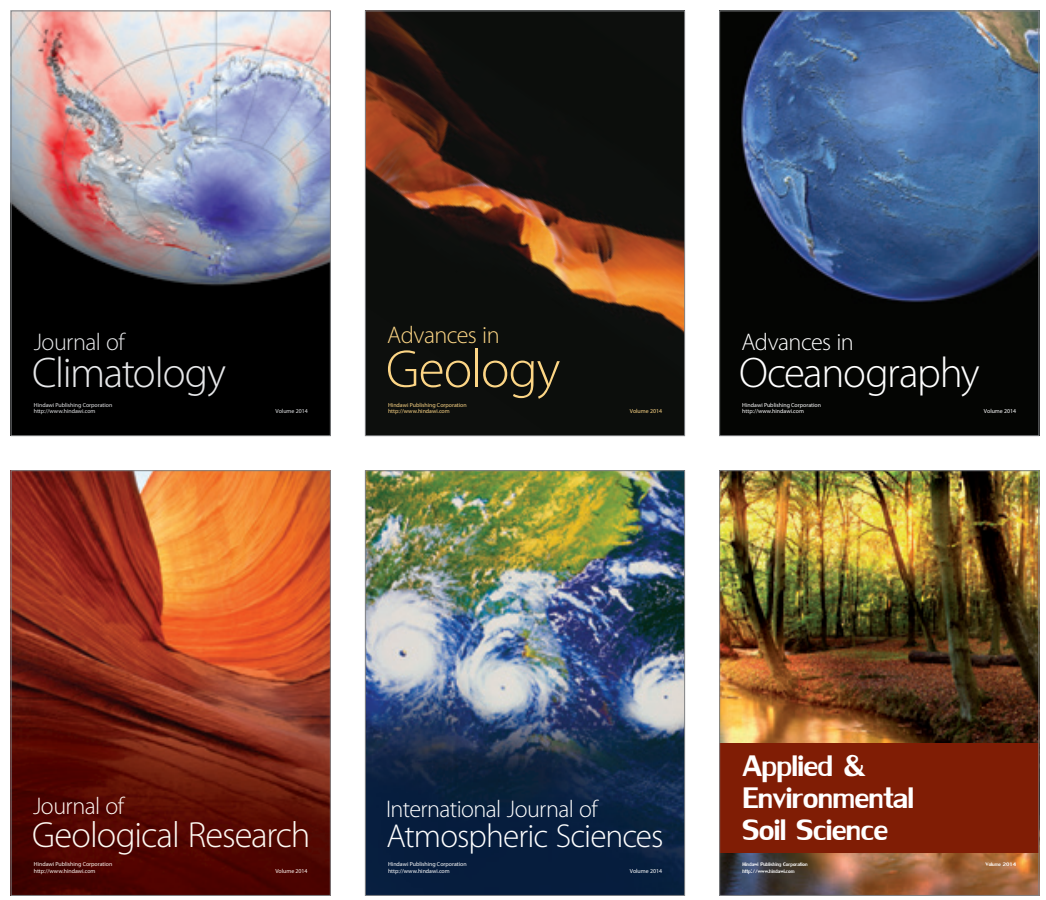
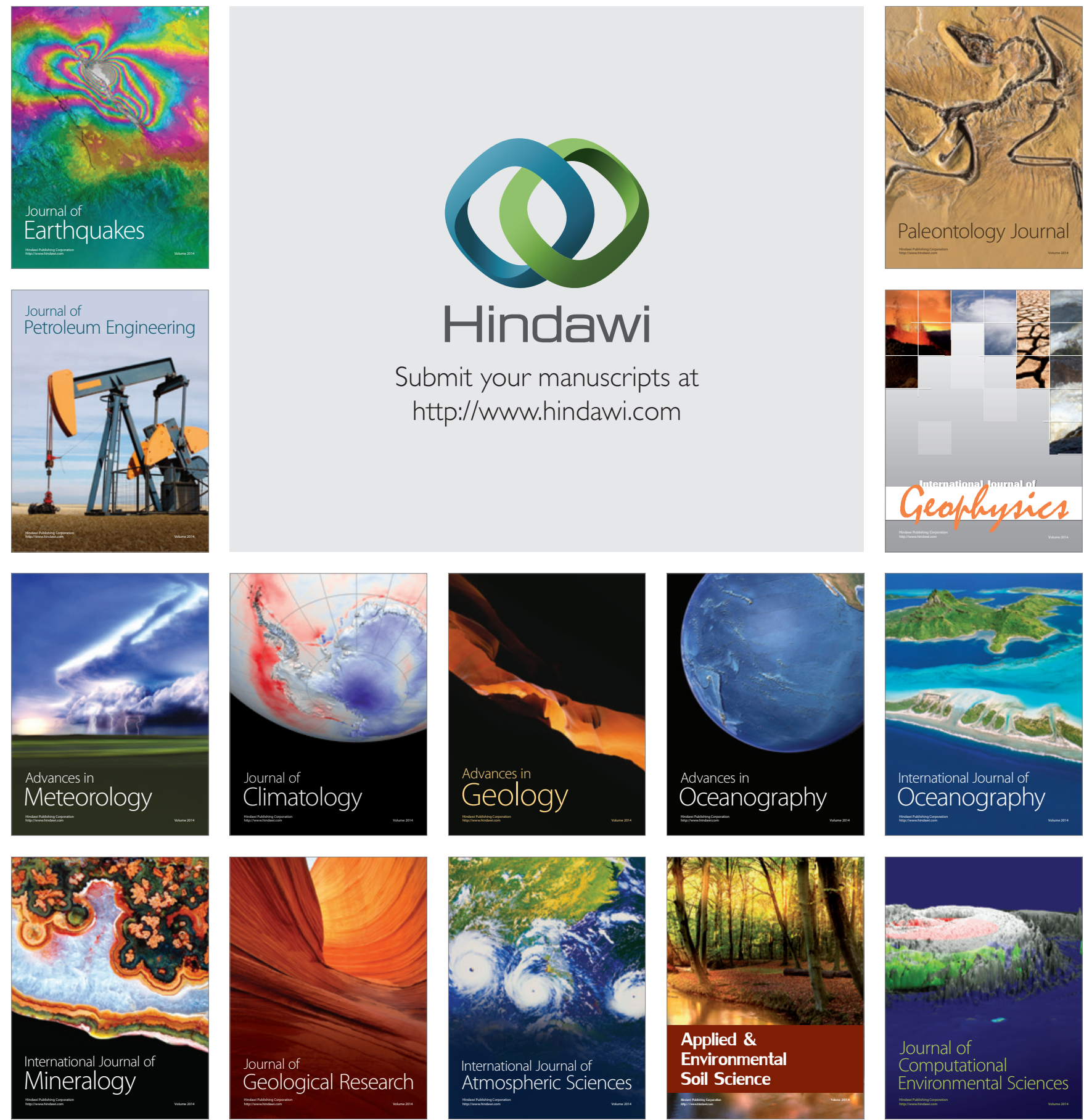